\title{
Visual word identification: Special-purpose mechanisms for the identification of open and closed class items?
}

\author{
DEREK BESNER \\ University of Waterloo, Waterloo, Ontario, Canada
}

\begin{abstract}
Bradley and Garrett (1983) proposed that separate specialized devices subserve the identification of open and closed class items in the left hemisphere, whereas only a single device subserves word identification in the right hemisphere. In this paper, an experiment is described that examined performance on open versus closed class items using Bradley and Garrett's stimulus set under conditions of foveal presentation. The results do not support the hypothesis that class-specific devices underlie word identification in intact subjects.
\end{abstract}

The notion that the human cognitive apparatus incorporates dissociable special-purpose systems for handling the syntactic aspects of language on the one hand and the content ideas on the other is well documented in the neuropsychological literature (e.g., Caramazza \& Berndt, 1978). Recently, it has been suggested that the influence of multiple special-purpose devices extends to the recognition of single words presented without any context. More specifically, Bradley and Garrett (1983) proposed the existence of separable specialized recognition devices, one for dealing with open class items (content words) and one for closed class items (functors). These specialized devices, moreover, are held to be available only to the left hemisphere. These claims rest on Bradley and Garrett's results of a lateralized word report experiment using intact subjects that found an overall right visual field (RVF) advantage coupled with a $13.5 \%$ advantage for open class over closed class items in the right visual field and no difference between open and closed class items in the left visual field (LVF).

The experiment reported here sought to examine further the empirical claim that word class differences are apparent in tachistoscopic report. Historically, various phenomena have been discovered under conditions of foveal presentation (e.g., name-physical letter matching [Posner \& Mitchell, 1967], the word superiority effect [Johnston, 1981], mental rotation [Cooper \& Shepard, 1973], the format-specific abbreviation superiority effect [Henderson \& Chard, 1976], memory scanning [Sternberg, 1966], the pseudohomophone effect [Coltheart, Davelaar, Jonasson, \& Besner, 1977]) and are followed by a laterality analysis that in each and every case is at

This research was supported by Grants U-0051 and A0998 from the Natural Sciences and Engineering Research Council of Canada. I am grateful to Keith McGowan for programming assistance, and to Doug Snow and Dave Rynard for running subjects. Address reprint requests to Derek Besner, Department of Psychology, University of Waterloo, Waterloo, ON N2L 3G1, Canada. least able to replicate the phenomena under conditions of RVF presentation (Barry, 1981; Besner, 1983; Cohen, 1972, 1975; Klatzky \& Atkinson, 1971; Krueger, 1975). Because Bradley and Garrett's (1983) word class effect was discovered under conditions of lateralized presentation, the present experiment sought to repeat the effect under conditions of foveal presentation.

If the language processing system is sensitive to word class differences at the word recognition level, this should surely be manifest under conditions of foveal presentation. It would be surprising if RVF presentation were a necessary condition for engaging special-purpose language processors, which Bradley and Garrett (1983) viewed as supporting syntactic inferences and parsing, particularly in view of the fact that, over a range of reading difficulties and presentation rates, comprehension is generally equivalent when material is read under normal paragraph format or under rapid serial visual presentation (RSVP) of single words at fovea (Juola, Ward, \& McNamara, 1982). Indeed, in trying to justify the translation from qualitatively distinct retrieval operations to quantitative differences in recognition accuracy, Bradley and Garrett appealed to findings from RSVP under conditions of foveal presentation. The implication is straightforward: Bradley and Garrett's hypothesis holds that foveal presentation engages the same special-purpose word recognition mechanisms as does RVF presentation. It thus seems clear that the finding of a word class effect at fovea would reinforce the view that a genuine phenomenon exists. On the other hand, a failure to find a word class effect at fovea would suggest that the word class effects found with lateralized presentation are not easily understood within the framework that is normally held to relate foveal and lateralized presentation.

\section{METHOD}

\footnotetext{
Subjects

The subjects were 20 undergraduate students recruited through advertisements placed around the campus and paid $\$ 3$ for their services.
} 


\section{Stimuli}

The stimuli were the 32 open class words and 32 closed class words making up the set used by Bradley and Garrett (1983). ${ }^{1}$ These stimuli are listed in the Appendix.

\section{Procedure}

The subjects, who participated individually, viewed the words on a 9-in. hooded monitor slaved to a PET 2001 microcomputer. On each trial a fixation point consisting of a $2 \times 2$ matrix of pixels was displayed. The subject's keypress was followed $112 \mathrm{msec}$ later by a display consisting of a lowercase word. Viewing distance was approximately $80 \mathrm{~cm}$. Individual letters were $4-5 \mathrm{~mm}$ high and $3 \mathrm{~mm}$ wide.

Bradley and Garrett's (1983) procedure was followed in that the subject was asked to report the whole word aloud; report of letters was not permitted. The subject was encouraged to guess and was scored correct if and only if the entire word was correct.

Several blocks of practice trials preceded the 64 experimental trials. The practice blocks contained 16 trials and were made up of mediumfrequency content words that did not appear in the experimental trials. Exposure duration was adjusted at the end of every practice block. Practice terminated when the subject's performance averaged between $40 \%$ and $60 \%$ correct for two consecutive blocks. The subject then saw one block of 64 experimental trials. Each word occurred once, and each subject saw a different random sequence of 64 trials. The only constraint on the sequence was that no more than three items from the same class be displayed in a row.

\section{RESULTS}

The mean proportions of correct identification of the stimulus items are .520 and .514 for closed class $(S E=$ $2.30)$ and open class $(S E=2.97)$ items, respectively. An analysis based on subjects failed to yield an effect of word class $(t<1)$. An item analysis also failed to yield an effect of word class $(t<1){ }^{2}$

\section{DISCUSSION}

The results of this study offer no support for the hypothesis that classspecific devices subserve visual word identification in intact subjects under conditions of foveal presentation. Related failures have occurred in studies by Gordon and Caramazza $(1982,1985)$, Samuel, Van Santen, and Johnston (1983), and Segui, Mehler, Frauenfelder, and Morton (1982).

\section{REFERENCES}

BARRY, C. (1981). Hemispheric asymmetry in lexical access and phonological encoding. Neuropsychologia, 19, 473-478.

BESNER, D. (1983). Deep dyslexia and the right hemisphere hypothesis: Evidence from the U.S.A. and U.S.S.R. Canadian Journal of Psychology, 37, 565-571.

Bradley, D. C., \& Garrett, M. F. (1983). Hemispheric differences in the recognition of closed and open class words. Neuropsychologia, 21, 155-159.

Caramazza, A., \& Berndt, R. S. (1978). Semantic and syntactic processes in aphasia: A review of the literature. Psychological Bulletin, 85, 898-918.

COHEN, G. (1972). Hemisphere differences in a letter classification task. Perception \& Psychophysics, 11, 139-142.

Cohen, G. (1975). Hemispheric differences in the utilization of advance information. In P. M. A. Rabbitt \& S. Dornic (Eds.), Attention and Performance $V$ (pp. 20-32). London: Academic Press.

Coltheart, M., Davelaar, E., Jonasson, J. T., \& Besner, D. (1977). Access to the internal lexicon. In S. Dornic (Ed.), Attention and Performance VI. Hillsdale, NJ: Erlbaum.

COOPER, L. A., \& SHEPARD, R. N. (1973). Chronometric studies of the rotation of mental images. In W. Chase (Ed.), Symposium on Visual Information Processing (pp. 75-176). New York: Academic Press.
Gordon, B., \& Caramazza, A. (1982). Lexical decision for open and closed class words: Failure to replicate differential frequency sensitivity. Brain \& Language, 15, 143-160.

Gordon, B., \& Caramazza, A. (1985). Lexical access and frequency sensitivity: Frequency saturation and open/closed class equivalence. Cognition, 21, 75-91.

Henderson, L., \& Chard, J. (1976). On the nature of the facilitation of visual comparison by lexical membership. Bulletin of the Psychonomic Society, 7, 432-434.

Johnston, J. C. (1981). Understanding word perception: Clues from studying the word superiority effect. In O. J. L. Tzeng \& H. Singer (Eds.), Perception of print: Reading research in experimental psychology (pp. 65-81). Hillsdale, NJ: Erlbaum.

Juola, S. F., Ward, N. J., \& McNamara, T. (1982). Visual search and reading of rapid sequential presentation of letter strings, words and text. Journal of Experimental Psychology: General, 111, 208-227.

Klatzky, R. L., \& AtKinson, R. C. (1971). Specialization of the cerebral hemispheres in scanning for information in short-term memory. Perception \& Psychophysics, 10, 335-338.

KRUEGER, L. E. (1975). The word-superiority effect: Is its locus visualspatial or verbal? Bulletin of the Psychonomic Society, 6, 465-468.

Posner, M. I., \& Mitchell, R. F. (1967). Chronometric analysis of classification. Psychological Review, 74, 392-409.

Samuel, A. G., Van Santen, J. P. H., \& Johnston, J. C. (1983). Reply to Matthei: We really is worse than you or them, and so are ma and pa. Journal of Experimental Psychology: Human Perception \& Performance, 9, 321-322.

Segui, J., Mehler, J., Frauenfelder, U., \& Morton, J. (1982). The word frequency effect and lexical access. Neuropsychologia, 20, 615-627.

STERNBERG, S. (1966). High speed scanning in human memory. Science, $153,652-654$.

\section{NOTES}

1. I am grateful to Merrill Garrett for providing me with a copy of Bradley's thesis. The stimulus set is drawn from her thesis.

2. The standard errors for Bradley and Garrett's (1983) experiment (collapsed across visual field) are 3.06 for closed class and 2.24 for open class.

\section{APPENDIX}

Proportion of Subjects

Who Correctly Identified

Item the Item

$\begin{array}{ll}\text { all } & .45 \\ \text { has } & .55 \\ \text { when } & .65 \\ \text { more } & .65 \\ \text { what } & .45 \\ \text { than } & .55 \\ \text { could } & .45 \\ \text { then } & .35 \\ \text { now } & .60 \\ \text { such } & .50 \\ \text { most } & .30 \\ \text { also } & .35 \\ \text { much } & .50 \\ \text { each } & .35 \\ \text { those } & .60 \\ \text { how } & .60 \\ \text { very } & .55 \\ \text { here } & .65 \\ \text { both } & .40 \\ \text { same } & .65 \\ \text { while } & .60\end{array}$


APPENDIX (Continued)

Proportion of Subjects Who Correctly Identified the Item

Item

since

few

every

less

yet

next

ever

thus

whose

soon

else

.60

.60

.60

.50

.60

.55

.55

.45

.55

.40

.50

Open Class

say $\quad 60$

make

man

time

new

year

state

give

work

look

place
APPENDIX (Continued)

Proportion of Subjects

Who Correctly Identified

Item the Item

$\begin{array}{ll}\text { world } & .65 \\ \text { life } & .65 \\ \text { hand } & .50 \\ \text { thing } & .50 \\ \text { turn } & .75 \\ \text { want } & .50 \\ \text { end } & .55 \\ \text { fact } & .50 \\ \text { plan } & .45 \\ \text { play } & .50 \\ \text { might } & .50 \\ \text { law } & .45 \\ \text { talk } & .55 \\ \text { job } & .50 \\ \text { easy } & .70 \\ \text { town } & .70 \\ \text { break } & .35 \\ \text { hard } & .70 \\ \text { deep } & .40 \\ \text { wish } & .40 \\ \text { farm } & .40\end{array}$

(Manuscript received for publication November 27, 1987.) 